\title{
Technical Analysis and Enlightenment of Renewable Energy
}

\author{
Shi (Jessee) Zhang1,2 \\ ${ }^{1}$ Shenyang Agricultural University, Shenyang, China \\ ${ }^{2}$ China University of Political Science and Law, Beijing, China \\ Email: jessee_zhang@163.com
}

How to cite this paper: Zhang, S. (Jessee) (2017) Technical Analysis and Enlightenment of Renewable Energy. Low Carbon Economy, 8, 106-117.

https://doi.org/10.4236/lce.2017.84009

Received: November 21, 2017

Accepted: December 18, 2017

Published: December 21, 2017

Copyright $\odot 2017$ by author and Scientific Research Publishing Inc. This work is licensed under the Creative Commons Attribution International License (CC BY 4.0).

http://creativecommons.org/licenses/by/4.0/

\begin{abstract}
This paper analyzes China's low-carbon technology through patent data of three major renewable energy sources which include nuclear energy, wind energy, biomass energy. The data platform used in this paper is from patent retrieval and analysis system in SIPO. According to the patent application in China, this paper studies regional map of technology, domain regional technology analysis, technology trend analysis and technology life cycle in the three renewable energy. From the above analysis, this paper sums up shortcomings in development of renewable energy and policies.
\end{abstract}

\section{Keywords}

China, Low Carbon technology, Renewable Energy, Patent

\section{Introduction}

Low carbon economy is one of the best models of global economic development [1]. Low carbon consumption is an important part of it. Low carbon consumption, industry, technology and urban construction are considered to be the most important content of low carbon economy. Low carbon consumption can promote the development of low-carbon industry, which makes the country into a virtuous cycle of low-carbon economy [2]. In the field of low-carbon energy technology, China's renewable resources are very rich. According to the Chinese government issued the "12th Five-Year plan" in 2011, which can see that the most important development field in low carbon economy and new energy industry are: Thermal power emission reduction, new energy vehicles, energy-saving buildings, industrial energy conservation and emission reduction, recycling of renewable resources and recycling economy, environmental protec- 
tion equipment, etc. The development of China's low carbon economy is still in its infancy, and the low carbon policy system is not mature enough. The government is speeding up the establishment of supervision mechanism of energy saving and emission reduction of the voluntary agreement, perfect the supervision mechanism of energy-saving product certification, and tax relief, policy incentives and other incentives as soon as possible to establish industry standards and norms in the energy services industry, to promote the full implementation of the contract energy management [3]! As a type of modern technology, the innovation of low carbon technology follows the general technology life cycle, to experience from basic research, technology development, demonstration projects to market promotion stage. Generally speaking, lack of core technology and R \& D strength are the common characteristics and development bottlenecks of most low carbon technologies. For example: carbon dioxide capture and storage technology in the R \& D demonstration phase; Wind power and solar energy technology without core technology support; Master the core technology of LED Technology [4]. According to the patent application in China, this paper studies regional map of technology, domain regional technology analysis, technology trend analysis and technology life cycle in the three renewable energy. The renewable energy technologies studied in this paper include nuclear energy, wind energy and biomass energy. The analysis data are 246 Chinese patent data in nuclear energy; The analysis data are 4134 Chinese patent data in wind energy; The analysis data are 438 Chinese patent data in Biomass energy.

\section{Literature Review}

China has initially formed the "renewable energy law" as the backbone of the legal system of renewable energy, in the development, utilization and management of renewable energy, the law can be realized. However, there are still insufficient laws and regulations in the legislation of renewable energy in China, and the comprehensive energy basic law has not been formulated. Some renewable energy legislation is rather deficient or the legislative force is low and the legal system is not perfect, and renewable energy laws are not closely linked to climate change. Our country should emphasize and highlight the development, utilization and management of renewable energy in the new energy basic law and the newly revised basic law of environmental protection. Combining the climate change law or the low-carbon economy promotion law with the revision of the renewable energy law, a legislative model for the implementation of a renewable energy law, the leading role of the government in promoting the development of renewable energy and the role of law in guiding and promoting the development of renewable energy. Renewable energy is the energy of sustainable development, the future energy, who masters the renewable energy, who will master the future of energy. In the face of potential energy crisis, global warming and deterioration of ecological environment, known as green energy, such as wind energy and solar energy, hydropower, biomass, geothermal energy, ocean energy, development 
and utilization of the renewable energy has been attention for the government and the whole society. As a mandatory and compulsory code of conduct and institutional resources, law plays an important role in promoting and protecting the sustainable development of renewable energy in China.

\section{Research Method and Database}

Considering many factors of China's legal development trend of new energy and environmental protection, this paper chooses three representative energy as the object of analysis the reason is: the nuclear energy is most closely related to environmental protection and energy; wind energy development is second worth of the energy in addition to solar energy; Bioenergy is the representative of energy in the micro world.

This paper analyzes the technology of China's three low-carbon renewable energy sources through China's patent data. The data platform used in this paper is patent retrieval and analysis system in SIPO. The retrieval method used in this paper is subject search, which is retrieved by searching the synonyms in the retrieval table, and the obtained data is accurate. SIPO is abbreviation of State Intellectual Property Office of the People's Republic of China, SIPO has collected the most comprehensive patent data in China. The patent retrieval and analysis system is also the most official analysis system. The author used keyword search to make the data more precise. Patent retrieval and analysis system in SIPO introduction:

Retrieval function contain regular search, table retrieval, drug thematic search, retrieval history, search results browsing, document browsing, batch download, etc. Analytical function contains quick analysis, custom analysis, advanced analysis, analysis report generation, etc.

The range of data: a collection of patent data of 103 countries, regions and organizations, as well as the citation, kin, legal status and other data, which covers the China, the United States, Japan and South Korea, Britain, France, Germany, Switzerland, Russia, the European Patent Office and the world intellectual Property Organization etc.

Data update: Chinese and foreign patent data, every Wednesday; family, legal status data, every Tuesday; citation data, updated monthly.

\section{Research Ground and Purpose}

In China, the design of renewable energy roadmap and its policy research have just started. In the development roadmap, in recent years, only the Chinese Academy of Sciences, the Chinese Academy of engineering and the Ministry of science and technology have carried out some research on the development of renewable energy technology [5]. Due to the imperfect database of China, China cannot use renewable energy technology life cycle method to comprehensively evaluate the development and utilization of new energy. At present, China has not studied several types of new energy sources [6]. Only a few scholars have 
made a comprehensive evaluation of a new type of energy technology.

To sum up, this paper studies the patent technology of the three types of new energy, analyzes the trend of technology and import countries, regional technical domain analysis, trend analysis in technology field, especially the use of technology life cycle analysis. From the above analysis, this paper is to observe the development of China's three major renewable energy technologies after the renewable energy legislation in 2005. According to the development of the three major renewable energy technologies, this paper analyzes the shortcomings and enlightenment of the current Chinese renewable energy law in three major renewable energy technologies.

\section{Analysis and Research}

\subsection{Overall Situation of Renewable Energy}

As shown in Figure 1, The general trend of patent application for renewable energy is rise. There are 21 patents in 2008; There are 37 patents in 2009; There are 57 patents in 2010; There are 61 patents in 2011; There are 78 patents in 2012; There are 66 patents in 2013; There are 58 patents in 2014; There are 89 patents in 2015; There are 90 patents in 2016; There are 80 patents in 2017.

As shown in Figure 2, The field of patent application for renewable energy are eight fields. There are 292 patents in H; There are 238 patents in F; There are 138 patents in C; There are 83 patents in G; There are 80 patents in B; There are 30 patents in $\mathrm{E}$; There are 17 patents in $\mathrm{A}$; There are 2 patents in $\mathrm{D}$. $\mathrm{H}$ is electricity; Fare mechanical engineering, lighting, heating, weapons and blasting; Care chemistry and metallurgy; G is Physics; Bare Work and transport; E is fixed building; A is Agriculture; $\mathrm{D}$ are textile and paper making.

As shown in Table 1, The first is $\mathrm{H} 02$ that are power generation, substation or distribution, there are 255 patents in H02; The second is F03 that are hydraulic, hydraulic engine, wind, elastic, gravity engine, other categories do not include mechanical or thrust engines, there are 100 patents in F03; The third is F24 that are heating, the stove or the ventilation, there are 93 patents in F24; The fourth is

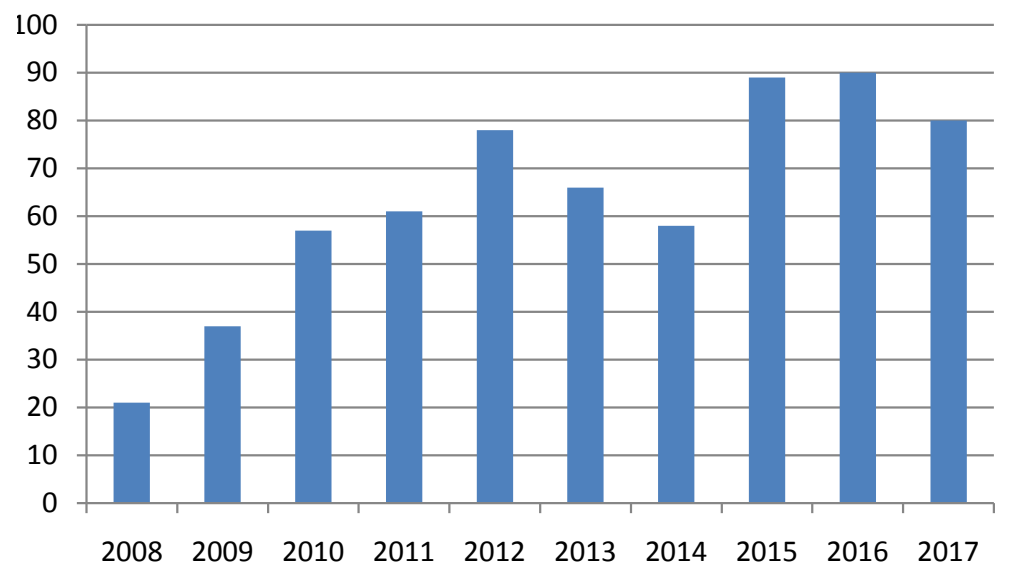

Figure 1. Trend of patent application for renewable energy. 


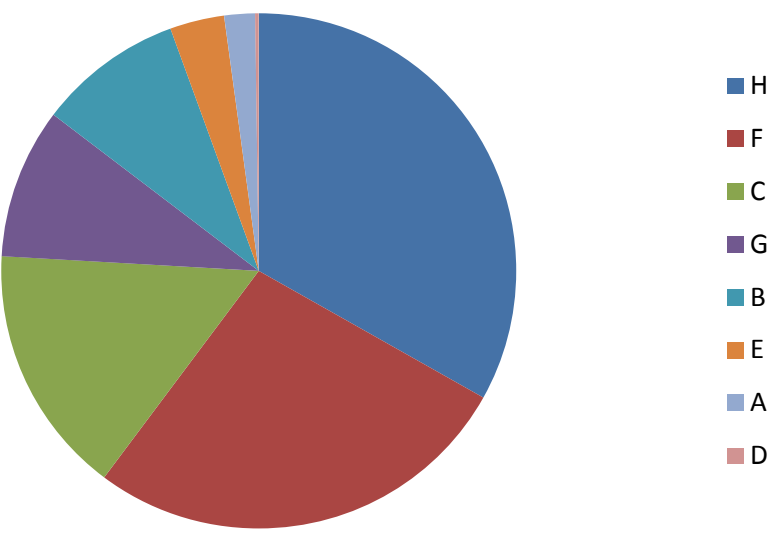

Figure 2. Application field of renewable energy patent.

Table 1. IPC ranking.

\begin{tabular}{lc}
\hline IPC & Number \\
\hline H02 & 255 \\
F03 & 100 \\
F24 & 93 \\
C10 & 57 \\
G06 & 46 \\
C12 & 43 \\
\hline
\end{tabular}

C10 that are oil, gas, coking industry, industrial gases containing carbon monoxide, fuels, lubricants or peat, there are 57 patents in C10; The fifth is G06 that are calculation, reckoning or counting, there are 46 patents in G06; The sixth is C12 that are biochemistry, beer, strong wine, juice wine, vinegar, microbiology, enzymology, mutation or genetic engineering, there are 43 patents in $\mathrm{C} 12$.

\subsection{Nuclear Energy}

As shown in Figure 3, most of China's nuclear energy technology is China's technology, and the main importing countries of nuclear technology are the United States, Japan, Germany, France and Russia. The import of nuclear technology in the United States imported technology accounted for 7.82\%, Japan accounted for $6.41 \%$ of imported technology, Germany imported technology accounted for $4.46 \%$, French imports of technology accounted for $1.67 \%$, accounted for $0.55 \%$ of Russia's imports of technology.

As shown in Figure 4, G21 Technology: The main technology is China's autonomous technology, some imported from other countries, the number of importing countries is the largest of all statistical technology; F01 Technology: There is no import countries, all technology are China's autonomous technology; G06 Technology: In addition to China's independent technology, imports mainly from the United States and Taiwan; A62 technology is imported from Germany; E21 technology is imported from France. 


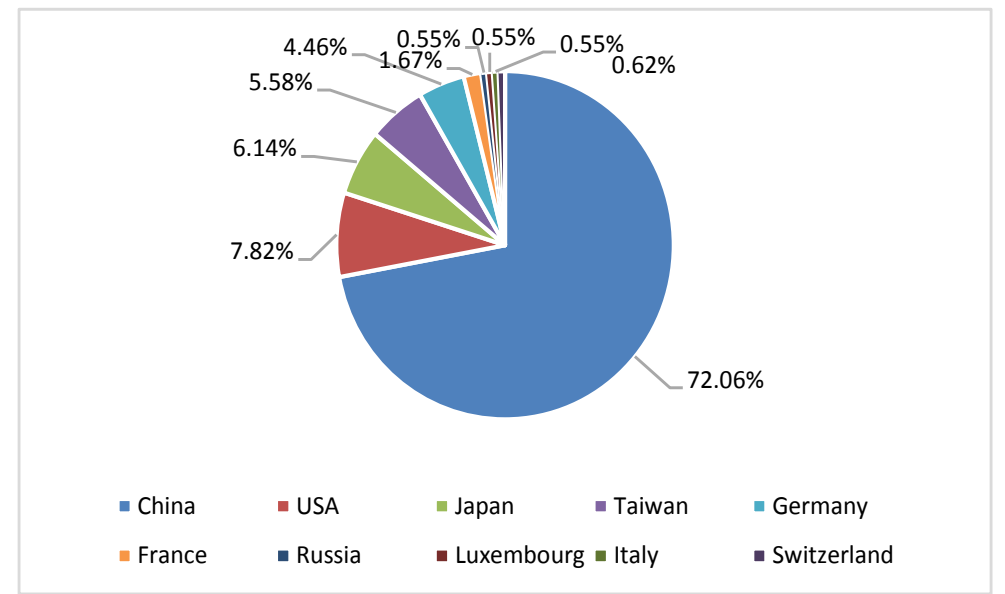

Figure 3. Regional map of nuclear energy technology.

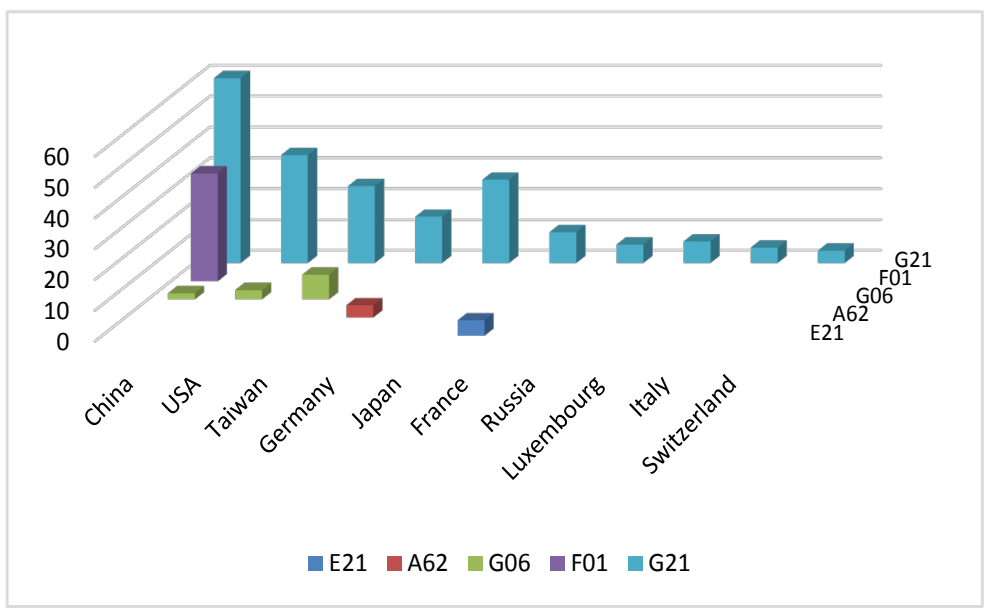

Figure 4. Domain regional analysis of nuclear energy technology.

As shown in Figure 5, The development trend of the 8 technologies in the period from 2008 to 2017 is in an unstable state. Generally speaking, G21 is in the rising stage.

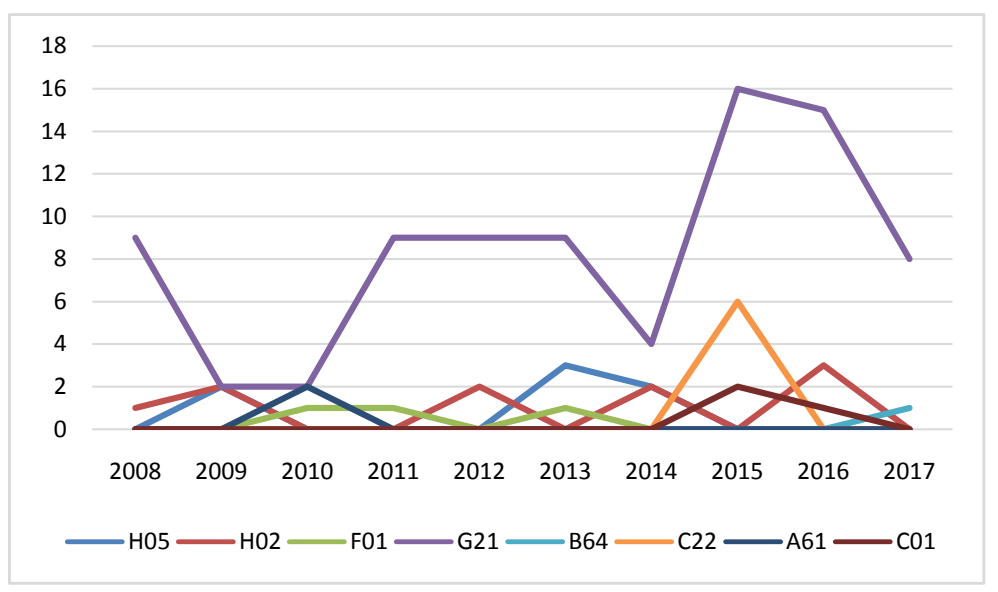

Figure 5. Trend analysis in nuclear energy technology field. 


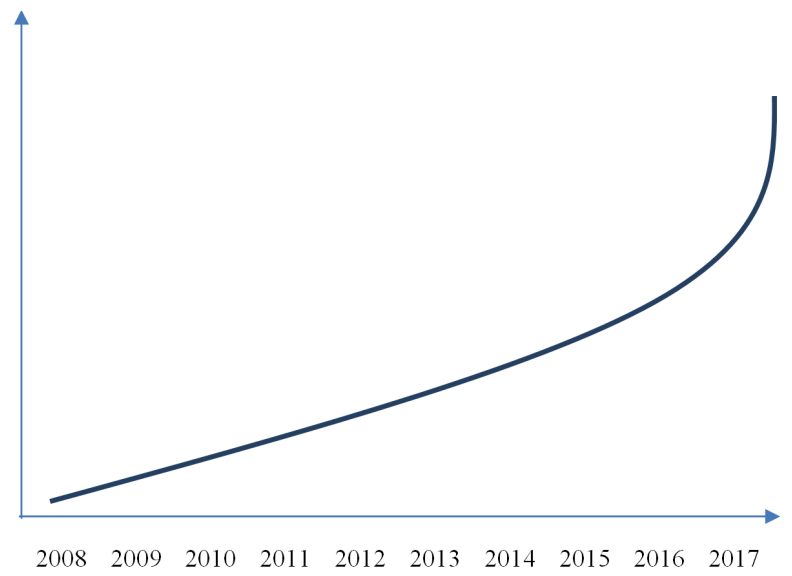

Figure 6. Life cycle of nuclear energy technology.

As shown in Figure 6, Almost all of the curves are in two stages: the number of patent applications and the number of applicants are relatively small, which is the initial stage of technology; and the number of patent applications and the number of applicants are increasing, which is the development stage of Technology. Only in these two stages, the technology start stage is more than the technology development stage.

\subsection{Wind Energy}

As shown in Figure 7, most of China's wind energy technology is China's technology, and the main importing countries of nuclear technology are Germany, USA, Canada, Denmark, Austria, Italy. The import of nuclear technology in the United States imported technology accounted for 1.07\%, Germany accounted for $6.11 \%$ of imported technology, Canada imported technology accounted for $0.18 \%$, Denmark imports of technology accounted for $0.16 \%$, Austria imports of

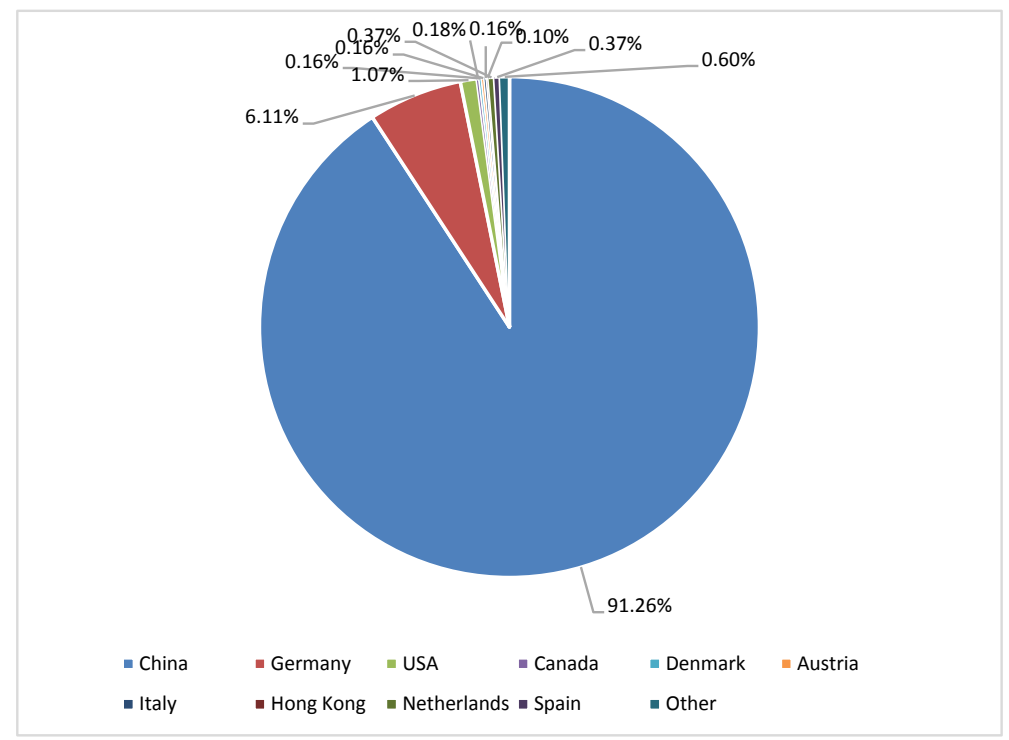

Figure 7. Regional map of wind energy technology. 
technology accounted for $0.16 \%$, accounted for $0.16 \%$ of Italy's imports of technology.

As shown in Figure 8, F03 Technology: The main technology is China's autonomous technology, some imported from other countries, the number of importing countries is the largest of all statistical technology; H02 Technology: The main technology is China's autonomous technology, some imported from other countries, the number of importing countries is the second of all statistical technology; B60 Technology: In addition to China's independent technology, imports mainly from Germany, Canada; B63 technology: In addition to China's independent technology, imports mainly from Germany, Spain; F16 Technology: The main technology is China's autonomous technology, some imported from other countries, the number of importing countries is the third of all statistical technology; B09 technology: In addition to China's independent technology, imports mainly from Canada.

As shown in Figure 9, The development trend of the 2 technologies in the period from 2008 to 2017 are in the rising stage. But they are down in the last year.

As shown in Figure 10, Almost all of the curves are in one stages: the number of patent applications and the number of applicants are increasing, which is the development stage of Technology.

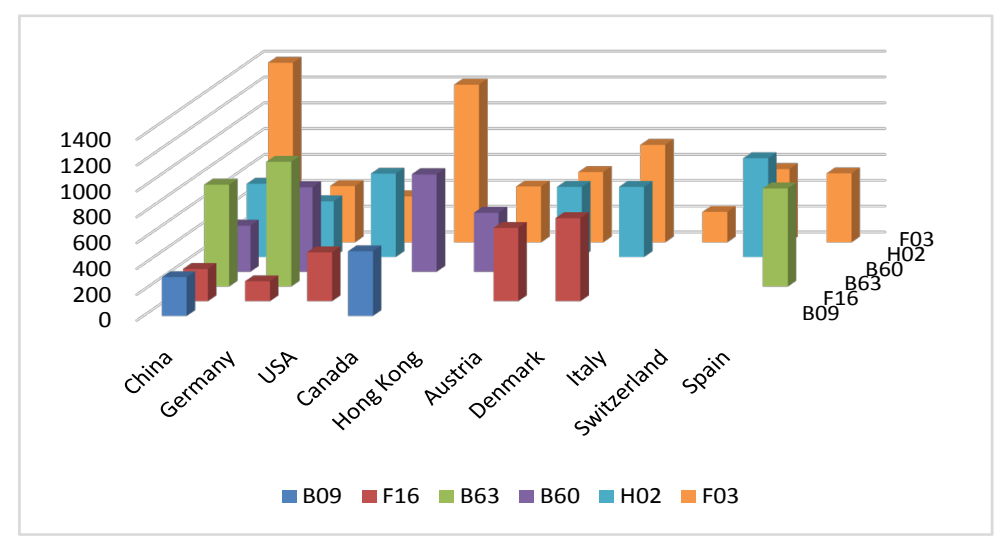

Figure 8. Domain regional analysis of wind energy technology.

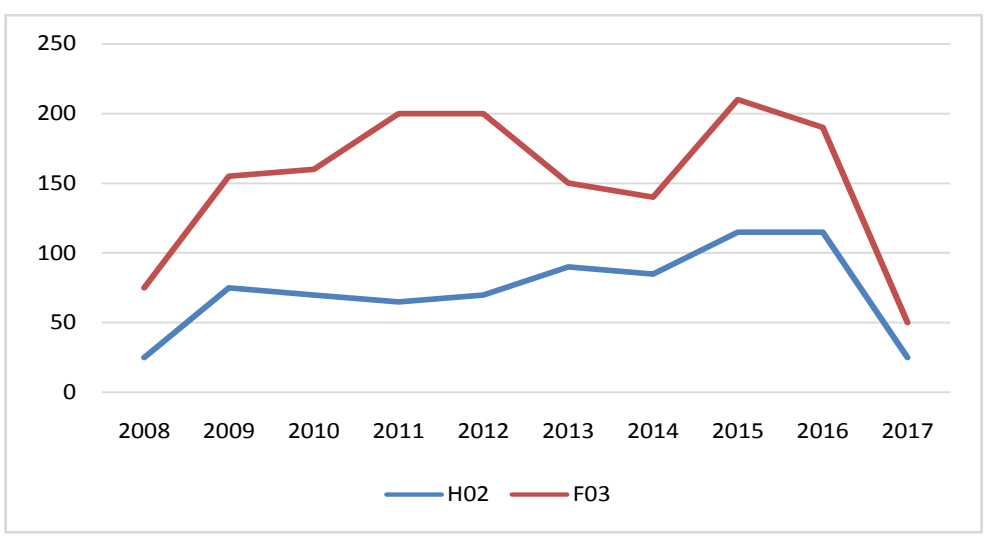

Figure 9. Trend analysis in wind energy technology field. 


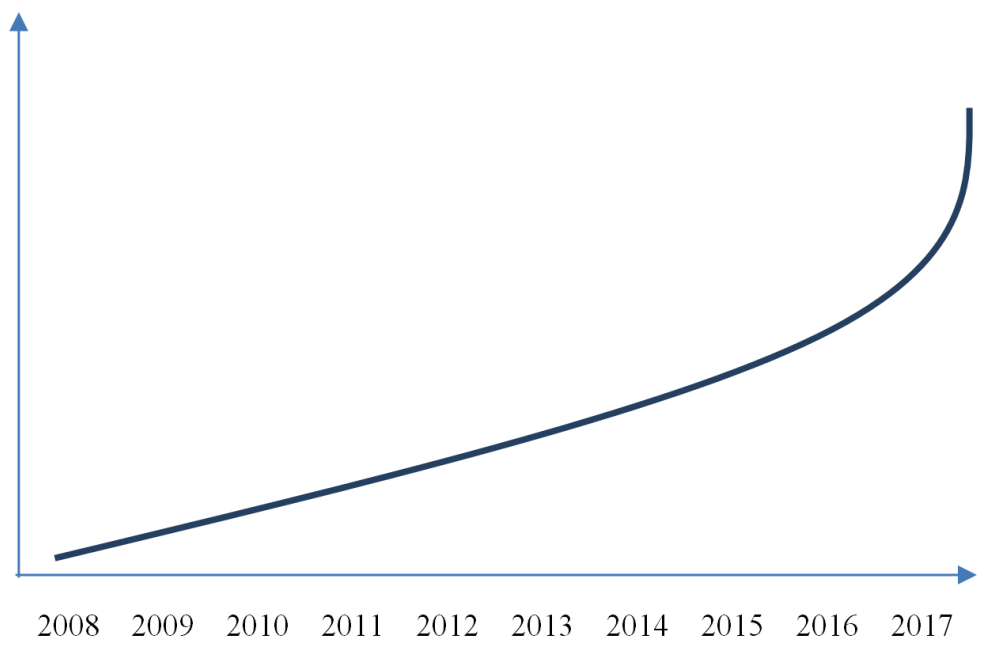

Figure 10. Life cycle of wind energy technology.

\subsection{Biomass Energy}

As shown in Figure 11, most of China's wind energy technology is China's technology, and the main importing countries of nuclear technology are Korea, Canada and Australia. The import of nuclear technology in Korea imported technology accounted for $0.74 \%$, Canada accounted for $0.49 \%$ of imported technology, Australia imported technology accounted for $0.25 \%$.

As shown in Figure 12, B09 technology: In addition to China's independent technology, imports mainly from Korea, Canada; F03 Technology: In addition to China's independent technology, imports mainly from Canada; F22 Technology: In addition to China's independent technology, imports mainly from Canada; C10 technology: In addition to China's independent technology, imports mainly from Korea, Australia; F24 technology: In addition to China's independent technology, imports mainly from Korea; C02, F22, C12, F23 Technology: There is no import countries, all technology are China's autonomous technology.

As shown in Figure 13, The development trend of the 4 technologies in the period from 2008 to 2017 is in an unstable state.

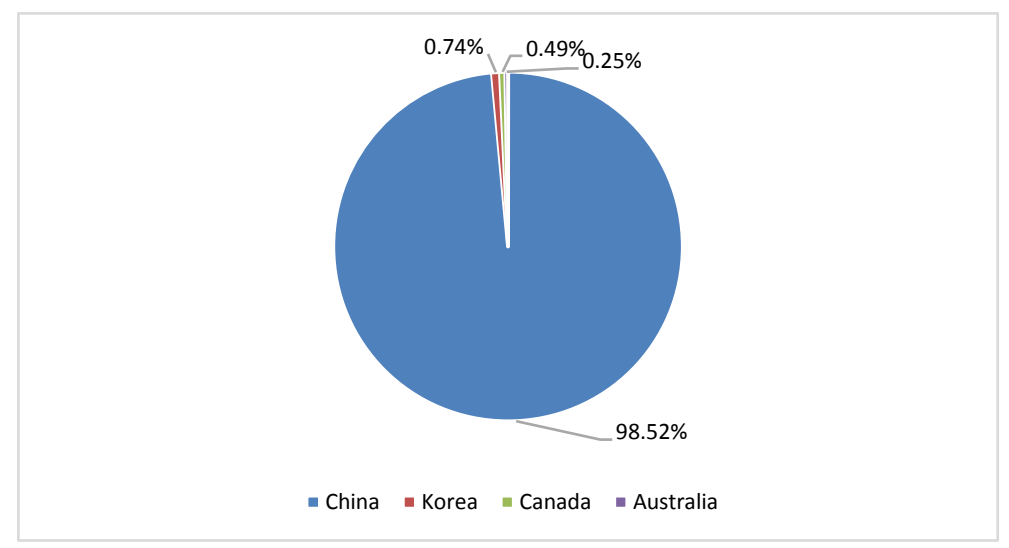

Figure 11. Regional map of biomass energy technology. 


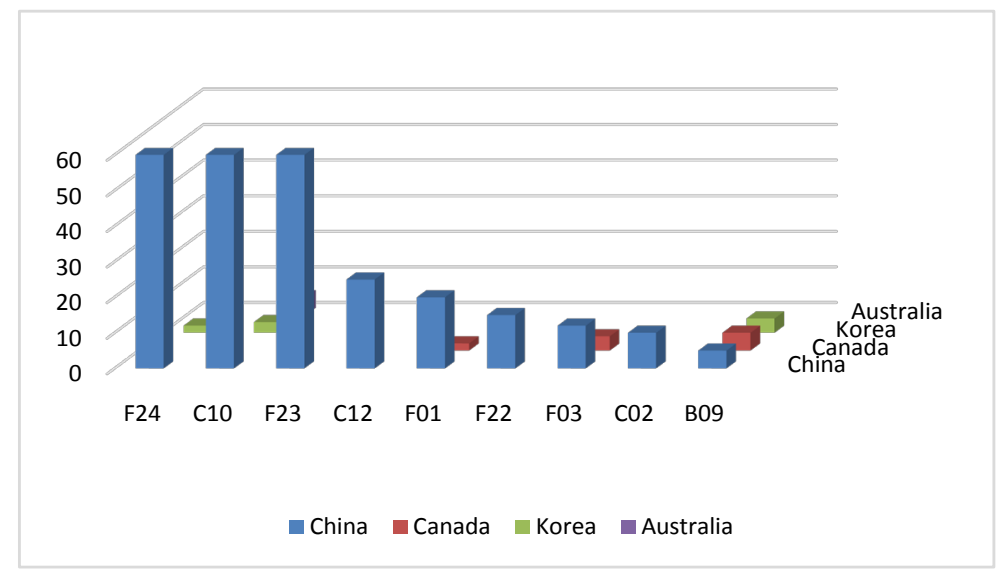

Figure 12. Domain regional analysis of biomass energy technology.

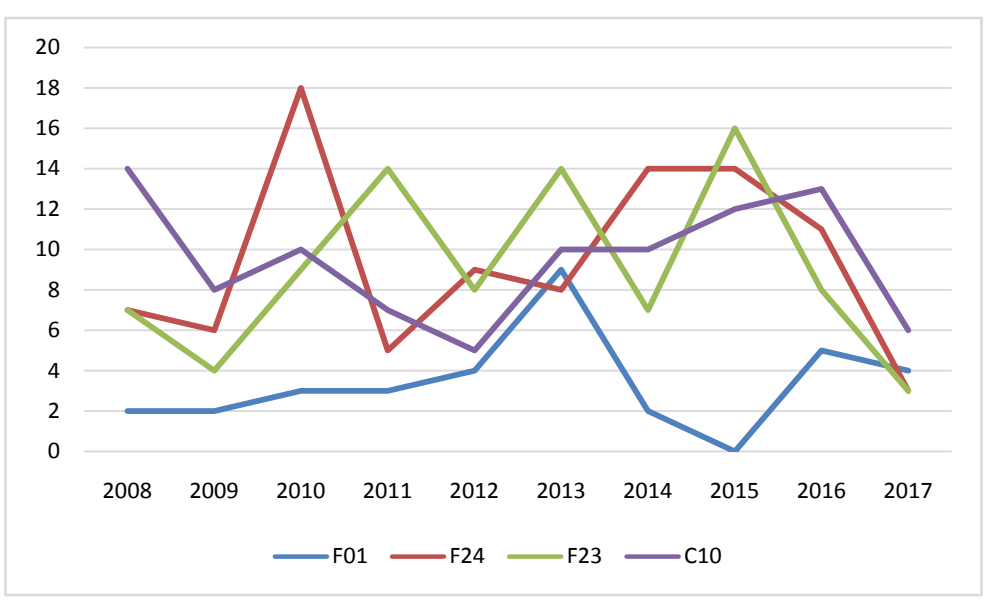

Figure 13. Trend analysis in biomass energy technology field.

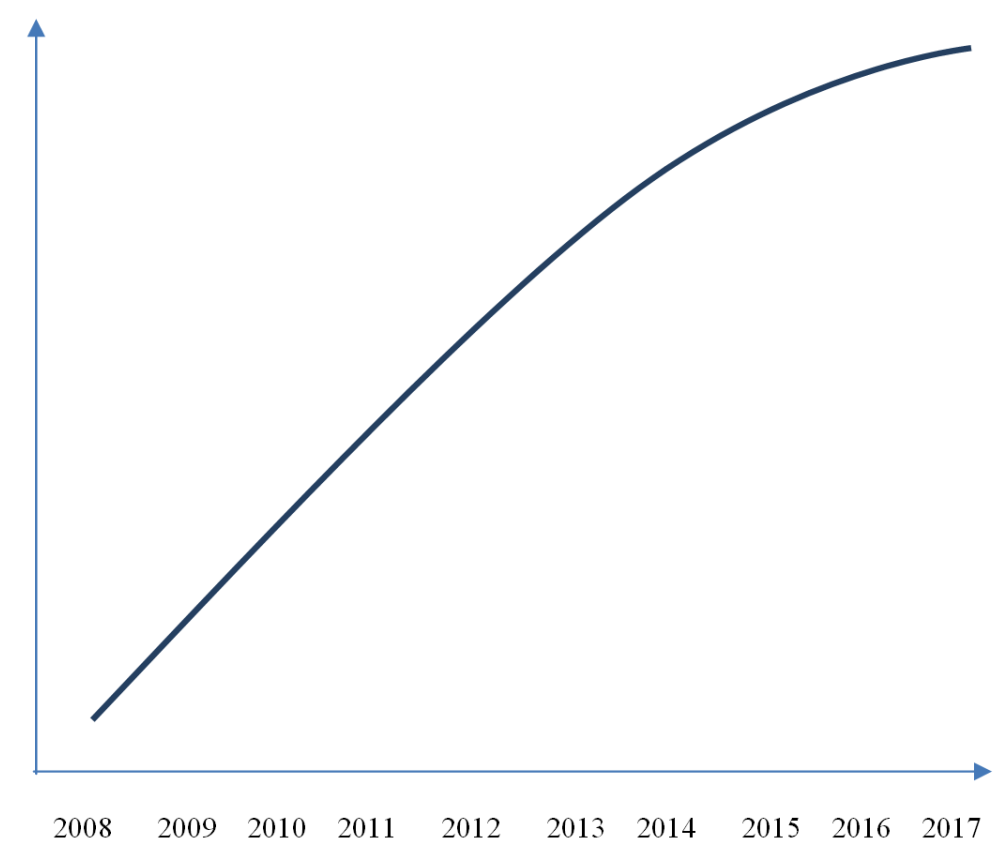

Figure 14. Life cycle of biomass energy technology. 
As shown in Figure 14, Almost all of the curves are in one stages: the number of patent applications and the number of applicants are increasing, which is the development stage of Technology.

\section{Conclusions}

After the renewable energy law was approved in 2005, it has played a very important role in speeding up the development and utilization of renewable energy in China. It has not only become an important legal guarantee to promote the development of renewable energy in China, but also has a positive impact on the international community. From the above analysis, we can see that technology life cycle of China's three major renewable energy is in the growth stage. Thus, China's renewable energy law plays an obvious role [7]. The development of renewable energy is a long process in China, from the above analysis we can see three major shortcomings: The above the three renewable energy sources, some of which rely on imports in china; three major technical field development of renewable energy is uneven; The direction of technology development on three renewable energy is not obvious. The shortcomings of China's renewable energy development are summarized from the above analysis, and there are many inspirations for China's renewable energy policy: Firstly, China needs to support the import of renewable energy technology into autonomous technology, and gives more encouragement to the innovation of independent technology; Secondly, China needs to make clear the overall development direction of renewable energy technology, so that the development of technology and economy in renewable energy field can be controlled; Finally, China needs to balance the development of renewable energy technology in various fields according to the policy [8]. According to the above renewable energy policy, not only can accelerate the pace of China's renewable energy development, but also can make China's renewable energy technology development by macro-control and industry and field control.

\section{References}

[1] Chen, L.Q. (2010) Low Carbon Economy: A New Trend of Global Economic Development. Journal of Hunan City University, 31, 46-52.

[2] Zhang, P. (2010) On the Response of Intellectual Property System to Low Carbon Technology Innovation. Science Technology and Law, 85, 29-32.

[3] Huang, D. (2010) Low Carbon Technology Innovation and Policy Support. China Science and Technology Forum, 2, 37-40.

[4] Zhao, Z. and Xiao, D.P. (2010) Bottlenecks and Countermeasures of Technological Innovation in Developing Low Carbon Economy. China Science and Technology Forum, 6, 41-46.

[5] Chen, X.C., Hu, T. and Tang, Y.J. (2010) Discuss on Low-Carbon Consumption. Consumer Economics, 26, 83-85.

[6] Wu, C.H. (2010) Roadmap of Technology Development for Low Carbon Innovation. Periodical of Chinese Academy of Sciences, 25, 138-145. 
[7] Langniss, O. and Wiser, R. (2003) The Renewables Portfolio Standard in Texas: An Early Assessment. Energy policy, 31, 527-35.

https://doi.org/10.1016/S0301-4215(02)00095-2

[8] Gireesh, S. and Joshua, K. (2011) Are Government Policies Effective in Promoting Deployment of Renewable Electricity Resource. Energy Policy, 39, 4726-4741. https://doi.org/10.1016/j.enpol.2011.06.055 